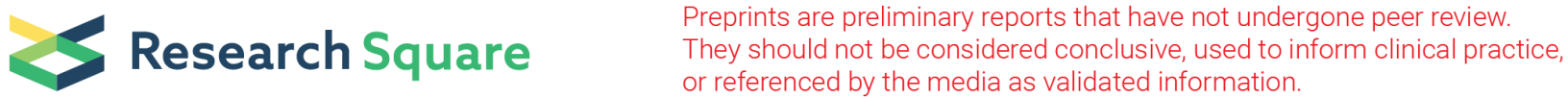 \\ Immune Cell Infiltration in Bladder Cancer
}

\author{
shanhui liu ( $\sim$ liushh2014@lzu.edu.cn )
}

Lanzhou University Second Hospital https://orcid.org/0000-0001-9254-5339

\section{Lanlan Li}

Institute of Urology, Lanzhou University Second Hospital; Key Laboratory of Urological Disease of Gansu Province; Institute of Gansu Nephro-Urological Clinical Center

\section{Shan Wu}

Gansu Provincial center for Disease Control and Prevention

\section{Wei He}

The second Clinical Medical College of Lanzhou University

\section{Jianzhong Lu}

Institute of Urology, Lanzhou University Second Hospital; Key Laboratory of Urological Disease of Gansu Province; Institute of Gansu Nephro-Urological Clinical Center

\section{Yan Tao}

Institute of Urology, Lanzhou University Second Hospital; Key Laboratory of Urological Disease of Gansu Province; Institute Nephro-Urological Clinical Center

\section{Jing Zhang}

Institute of Urology, Lanzhou University Second Hospital; Key Laboratory of Urological Disease of Gansu Province; Institute of Gansu Nephro-Urological Clinical Center

\section{Shengjun Fu}

Institute of Urology, Lanzhou University Second Hospital; Key Laboratory of Urological Disease of Gansu Province; Institute of Gansu Nephro-Urological Clinical Center

\section{Zhiping Wang}

Institute of Urology, Lanzhou University Second Hospital; Key Laboratory of Urological Disease of Gansu Province; Institute of Gansu Nephro-Urological Clinical Center

\section{Research article}

Keywords: Bladder cancer, tumor-infiltrating immune cells, CIBERSORT, TCGA, Tregs, Macrophages M2

Posted Date: August 6th, 2019

DOI: https://doi.org/10.21203/rs.2.11176/v1

License: (c) (i) This work is licensed under a Creative Commons Attribution 4.0 International License. Read Full License 


\section{Abstract}

Background Bladder cancer is one of the most common malignant diseases with high recurrence rates worldwide. Although immunotherapy has been applied in bladder cancer for a long period of time, the tumor-infiltrating immune cells (TIICs) in bladder cancer has not been systematical investigated. Methods CIBERSORT, a versatile computational method for quantifying cell fractions from bulk tissue gene expression profiles (GEPs), was applied to calculate the TIICs fraction proportion in normal bladder tissues and in bladder cancer tissues with the TCGA data. Results compared to normal bladder tissue, B cells naïve, T cells CD4 memory resting and Mast cells resting fractions proportion decreased, and NK resting, macrophages $\mathrm{M} 0$ and macrophages $\mathrm{M} 1$ increased. In BLCAs tissue, pro-tumorigenic related immune cells were negatively correlated with anti-tumor immune cells. New tumor with locoregional had high fraction proportion of macrophages M0 and macrophages M1. Dendritic cells activated, Monocytes, macrophages M1, Tregs and T cells follicular helper significantly increased in low grade BLCAs. Tregs had a high proportion in BLCAs patients accepted low radiation dose. Conclusions This study indicates that macrophages $\mathrm{M} 2$ and Tregs could be the promising immunotherapy targets combined radiotherapy in BLCAs. The result provides valuable information to understand the immunity status in BLCAs.

\section{Background}

Bladder cancer (BLCA) is one of the most common cancers worldwide. In 2019, there will be more than 80,000 new BLCA cases diagnosed and 17,000 deaths in the USA[1]. The BLCA incidence in men is about four times higher than in women. Hormonal profiles partly contributed to this disparity in gender[1, 2]. Non-muscle invasive bladder cancer (NMIBC) and muscle invasive bladder cancer (MIBC) are generally considered as two forms BLCAs[3]. NMIBC could be divided into low grade non-muscle invasive bladder cancer (LG-NMIBC) and high grade non-muscle invasive bladder cancer (HG-NMIBC) according to the oncological natural histories difference.More than $70 \%$ BLCA patients are newly diagnosed with NMIBC. Radiation therapy, chemotherapy, immunotherapy and surgery are the main therapeutic measures. Although there are variety of treatments options available for NMIBC currently, high recurrence and progression rates are the main obstacles to the NMIBC treatment. Treatment options for MIBC are limited. Therefore, the development of more specific and efficient targeting strategies in BLCA treatment is urgent.

Tumor infiltrating immune cells (TIICs) is closely associated with clinical outcome in BLCA [4, 5].

Therefore, immunotherapy has been applied to treat NMIBC for more than 40 years for Morales et al first used Bacillus Calmette-Guerin (BCG) to treat bladder cancer patients in 1976[6]. Now, intravesical BCG instillation has been one of the most effective treatments for NMIBC and one of the most successful biotherapies for cancer[7]. Unfortunately, BCG immunotherapy still fails in about $40 \%$ of NMIBC patients. Recently research results partly ascribe BCG instillation failure to TIICs. M2 macrophages and Treg cells, which secrete immunosuppressive cytokines $₫$ have been discovered associating with BCG immunotherapy failure[8-10]. Also, radiotherapy contributes to recruiting tumor associate macrophages and Tregs to the tumor environment $[11,12]$. Therefore, further characterization of the TIICs in BLCA treatment is essential to improve the clinical outcome[13]. Herein, we systematically analyzed the TIICs in 
normal tissue and in BLCAs tissue by the means of CIBERSORT, a useful tool to estimate the proportions of 22 immune cell types [14]. This work may helpful to identify new therapeutic targets for BLCA treatment.

\section{Methods}

\section{Bladder cancer datasets and normal controls datasets acquisition}

Gene expression data of bladder cancer patients and normal controls was collected from TCGA database by the TCGA GDC transfer tool. 414 bladder cancer samples and 19 normal control samples were included. The mRNA expression profiles matrix was obtained by merged each sample mRNA expression data. Then non-protein coding genes were filtered. The retained gene name was annotated to get gene expression matrix.

\section{Collection of Clinicopathological Data}

Clinical information was acquired and processed by TCGA-Assembler Module A and Module B. The information on age at diagnosis, gender, tumor grade, stage status and metastasis pathologic was extracted for further analysis.

\section{Estimated Immune Cell Type Fractions}

LM22 signature matrix, which contains 547 genes expression information from 22 human leukocytes, including seven T-cell types, three macrophage types, three B cell types, natural killer (NK) cells, and myeloid subsets, was downloaded from the CIBERSORT web portal (https://cibersort.stanford.edu/index.php). The gene expression matrix with annotation was used to calculate the LM22 fractions by the algorithm method with 100 permutations. The inferred fractions of immune cell populations produced by CIBERSORT were summed up to one matrix and be interpreted for comparison.

\section{Statistical analysis}

R software (version 3.5.3) and origin 8.0 were applied for all statistical analyses. LM22 correlation index was calculated with corrplot Package. Two-tailed Student $t$ tests or One-way- ANOVA was performed for statistical analysis. The $p$ values less than 0.05 were considered as statistically significant.

\section{Results}

\section{Data Set Containing 414 Bladder Cancer Samples and 19 Normal Bladder Tissue Samples}

In this study, a summary of available patient characteristics were presented in Table 1. Bladder cancer samples were classified by age at diagnosis, gender, tumor grade, stage status and metastasis pathologic. 


\section{Immune composition differs in Bladder Cancer Tissues and Normal Bladder Tissues}

The gene expression matrix was obtained from the TCGA download datasets. Then CIBERSORT algorithm was applied to define the immune cell fraction proportion of BLCA tissues and normal bladder tissues. Figure 1 showed the immune cell fraction proportion in bladder cancer tissues and normal bladder tissues. Compared with normal bladder tissue, the B cells naïve, T cells CD4 memory resting, Mast cells resting fractions in bladder cancer tissue were generally lower, whereas the fractions of NK cells resting, Macrophages M0 and M1 cells were higher in bladder cancer tissue (table 2 and figure 1 ).

\section{Correlation with 22 immune cell types in bladder cancer tissues}

The degree of tumor immune cell infiltration is a crucial factor in cancer development. Interactions between tumor infiltrating leukocytes (TILs) existed in tumor microenvironment [15-17]. However, the TILs interaction in bladder cancer was rarely reported. To further elucidate the interdependence between the degree of immune cell fraction and immune cell composition in bladder cancer tissues $₫$ we calculated the coefficient of association of 22 immune cell types in bladder cancer tissues with the corrplot package. Our results showed that macrophages M2, which was much abundant in BLCA囚negative correlated with numerous anti-tumor immunity cells, including NK resting $\unrhd T$ cells $C D 8, T$ cells $C D 4$ naive $囚$ mast cells activated, plasma cells $₫ B$ cells naïve, $B$ cells memory, $T$ cells follicular helper and Dendritic cells activated. Tregs $\ a$ subpopulation of $T$ cells that are immunosuppressive, negative correlated with Macrophages M1 cells $₫ r=-0.21$ \and T cells CD4 memory activated $(r=-0.24)$. T cells CD8 positively

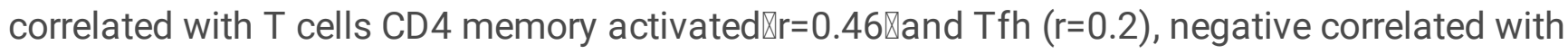
Macrophage M2 ( $r=-0.17)$, Macrophage M0 ( $r=-0.33)$ and T cells CD4 memory resting $(r=-0.4)$. T cells CD4 memory activated positively correlated with macrophages M1 ( $r=0.33)$, T cells CD8 $(r=0.46)$ and NK

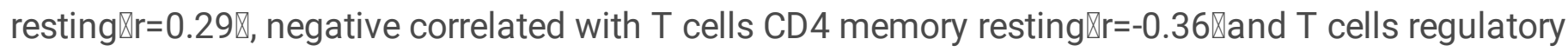
『r=-0.24凶(figure 2).

\section{Composition of immune cells in new tumor}

The new tumor event type and site had important prognostic value in BLCA and other cancers [18]. To investigate the composition of immune cells in new tumor, we analysised the immune cells fraction change in new type or site tumor. Results showed that new Primary Tumor had a high fraction of $T$ cells CD4 memory resting, $T$ cells naïve, $T$ cells follicular helper and had a lower fraction of plasma cells, macrophages M2, macrophages M0, compared to locoregional, distant metastasis type tumor.

When we analyzed the immune cells fraction in different types of bladder cancer tissues, It was found dendritic cells and resting macrophages $\mathrm{M} 0$ maybe correlate with tumor metastasis (figure3). compared to metastasized to other sites, when cancer cells metastasized to the lymph node only $\llbracket$ macrophages M0 content has a great change $\varangle$ which implied high content of Macrophages $\mathrm{M} 0$ may be a risk factor for metastasis. When bladder cancer cell transfer to bone, fraction high content of the dendritic cells resting was found in the bladder cancer tissue. 


\section{Immune cells fraction change in high and low grade BLCA}

To explore the relationship between tumor immune cell infiltration and the bladder cancer grade, we found T cells CD4 memory activated, Macrophages M0 and macrophages M1 fraction proportion increased in high grade BLCA tissues (fig.4a, d, e). However, regulatory T cell-based immunosuppressive effect was weak in high grade BLCA cancer tissue for Treg is much less abundant in high grade BLAC tissue than in low grade BLCA tissue (fig.4b). Monocytes decreased in high grade BLCA tissues (fig.4d). Dendritic cells activation was inhibited in high grade BLCA tissue for the activated Dendritic cells decreased significantly and Dendritic cells resting fraction increased significantly compared to in low grade BLCA tissue (fig.4f, g).

\section{Tumor immune cell infiltration and radiation in bladder cancer}

Radiotherapy was one of the most common treatments in the management of various types of cancer. Over half of people who were treated for cancer had accepted with radiotherapy $[19,20]$. However》 radiotherapy could contribute to the anti-immunogenic effect by recruiting TAMs and MDSCs in tumor microenvironment[21, 22]. The tumor immune cell infiltration in bladder cancer which accepted with radiotherapy remains unclear. Our work demonstrated that radiation dose could cause the tumor immune cell infiltration change (figure5). In low radiation dose group, Tregs increased. In high radiation dose group, macrophages M2 increased. When studying TIICs fraction proportion in BLCA patient with different radiotherapy sites, we found macrophages $\mathrm{M} 2$ had a high fraction proportion in local recurrence, T cells CD4 memory resting and Macrophages M0 had a high fraction proportion in distant recurrence, macrophages M2 and T cells CD8 fraction proportion increased in local recurrence.

\section{Discussion}

Tumor microenvironment acts as an important role in the development and progression of cancer [23, 24]. In this work, we aim to clarify the immune microenvironment in BLCA. As far as we know, this is the first time to comprehensively assess the immune infiltration in BLCA based on the deconvolution of bulk gene expression data.

Human T cells and B cells could regulate acquired immune system by secreting cytokines, creating antibodies, etc. The anti-tumor ability was impaired in tumor microenvironment of T cells and B cells[25]. Our results showed that the fraction of $B$ cells and T cells CD4 memory resting decreased in BLCA. It may mean $B$ cells and $T$ cells origination exhaustion in BLCA. This could contribute to the impaired anti-tumor activity of $B$ cells and $T$ cells. Furthermore, we observed that effecter $T$ cells and $B$ cells, including $T$ cells CD8/ T cells CD4 memory activated / T cells follicular helper/plasma cells $\$ negatively correlated with protumorigenic related immune cells, such as Tregs/macrophages M2, etc.

Macrophages, which could mediate the antigen presentation process, are major components in cancer immune infiltration[26]. It is also characterized by plasticity and heterogeneity. Macrophages M0 could differentiate into macrophages M1 or macrophages M2 under different cytokines stimulation. The 
disturbance of macrophages M1/M2 balance could alter antitumor effects. In human bladder cancer, increased infiltration of tumor associated macrophages has been showed to be associated with the poor clinical prognosis [27]. Some researcher suggested that targeting macrophage may be a promising strategy for anticancer therapy $[28,29]$. Our analyses revealed t a high level of macrophages M0 and M1 existed in BLCA. Although macrophages $\mathrm{M} 0$ and macrophages $\mathrm{M} 1$ fraction increased in BLCA, compared to normal, the M1/M2 balance and M1/total macrophages balance did not shift.

Mast cells contain large granules, which could release the immunomodulatory and vasoactive molecules. Mast cells infiltration has been showed involved in several types of cancer physiological and pathological conditions[30]. Previous studied showed that mast cells influence BLCA patient outcomes [31, 32]. Mast cells could enhance bladder cancer metastasis by increasing CCL2/CCR2/EMT/MMP9 signals axis. In this study, we discovered that total mast cells and mast cells resting decreased in BLCA. Mast cells negative correlated with several types of immune cells, such as macrophages M1/T cells CD8/T cells CD4 memory activated/T cells follicular helper, etc. the result consists with its pro-tumorigenic role in BLCA[31].

More interesting, our data firstly exposed the TIICs fraction in different types of new tumor event type and site. New primary tumor seemed had a T cells pool, T cells CD4 memory resting and T cells naïve, compared to locoregional and distant metastasis BLCA. It suggested that activation of T cells may be a useful strategy to BLCA patients with new primary tumor. Furthermore, TIICs fraction difference also existed in different type of metastasis BLCAs. These results could be helpful to improve BLCAs treatment.

TIICs have been reported in association with tumor grade [10,33]. Herein, the association between TIICs and tumor grade was also investigated. A high estimated Tregs fraction proportion was observed in low grade BLCA. A high estimated Dendritic cells resting fraction proportion was observed in high grade BLCA. It suggested that Regulatory T Cell-Based Immunosuppressive Effect may play an important role in low grade BLCA and inhibition the Tregs function in low grade BLCA may be a useful immunotherapy in treating low grade BLCA. Moreover, Dendritic cells resting activation may be another therapy strategy for high grade BLCA[34].

Radiotherapy is generally applied to the cancerous tumor for its cytotoxicity. However, radiotherapy could not only cause damage to cancer cells, but also leading to immunologic cells death indiscriminately [35, 36].

We found TIICs fraction proportion are different in BLCA patients who accepted different radiation dose or accepted with different radiotherapy sites. Interestingly, results showed that Tregs are more sensitive to high radiation dose. It determined that combining immunotherapy by inhibiting of Tregs activity with radiotherapy provided an improved treatment for BLCA rather than single low radiation dose [37]. Our data further showed the TIICs fraction proportion in patients with different radiotherapy sites. Results implied that macrophages M2 may act as a vital role in local recurrence and in local recurrence and radiation therapy combined $\mathrm{M} 2$ inhibition may be more useful to these patients. In distant recurrence patients, T cells CD4 memory resting and Macrophages M0 had a high fraction proportion. Activation T 
cells CD4 memory resting and Macrophages M0 may be a promising strategy to improved radiotherapy effect to distant recurrence patients.

\section{Conclusions}

This is the first time to explore the TIICs in BLCA by using the accurately estimate tumor-infiltrating leukocytes analysis tool, CIBERSORT. The complex relationship between different kinds of TIICs was further revealed. Furthermore, we studied the TIICs fraction proportion in BLCAs patients in high or low grade, and the relationship between TIICs fraction proportion and radiotherapy. More importantly, we highlighted the promising immunotherapy value of Tregs, macrophages M2, etc. Our work advances the understanding of TIICs and provides valuable resources for research to improve immunotherapy.

\section{Abbreviations}

BLCA: bladder cancer

TIICs: tumor-infiltrating immune cells

TILs: tumor infiltrating leukocytes

TCGA: The Cancer Genome Atlas

GEPs: gene expression profiles

BCG: Bacillus Calmette-Guerin

\section{Declarations}

\section{Ethics approval and consent to participate}

This article does not contain any studies with human participants or animals performed by the author.

Consent for publication

Not applicable.

\section{Availability of data and materials}

Data on gene expression and corresponding clinical information were downloaded from The Cancer Genome Atlas (TCGA, https://cancergenome.nih.gov/) prostate cohort through the R package "TCGAAssembler (06/04/2018)" in January 2019[38, 39].

\section{Competing interests}

The authors declare that they have no competing interests. 


\section{Funding}

This work was supported by the Cuiying Scientifc and Technological Innovation Program of Lanzhou University Second Hospital (Grant no. CY2018-QN13) and by the Cuiyingxuezipeiyu Scientific Program of Lanzhou University Second Hospital (Grant no. CYXZ-08).

\section{Authors' contributions}

SL and LL contributed to the study design. WH, SW, JL and YT performed the data collection and analysis. JZ, SF and ZW prepared the manuscript. All authors read and approved the final manuscript.

\section{Acknowledgements}

Not applicable.

\section{References}

[1] SIEGEL R L, MILLER K D, JEMAL A. Cancer statistics, 2019. CA: A Cancer Journal for Clinicians. 2019; 69(1): 7-34. doi:https://doi.org/10.3322/caac.21551.

[2] DESANTIS C E, MILLER K D. Cancer statistics for African Americans, 2019. 2019; 69(3): 211-33. doi:https://doi.org/10.3322/caac.21555.

[3] KAMAT A M, BAĞCıOĞLU M, HURI E. What is new in non-muscle-invasive bladder cancer in 2016 ? Turkish journal of urology. 2017; 43(1): 9-13. doi:https://doi.org/10.5152/tud.2017.60376.

[4] PFANNSTIEL C, STRISSEL P L, CHIAPPINELLI K B, SIKIC D, WACH S, WIRTZ R M, et al. The Tumor Immune Microenvironment Drives a Prognostic Relevance that Correlates with Bladder Cancer Subtypes. Cancer immunology research. 2019; 18(1): e1455-e6. doi:https://doi.org/10.1158/2326-6066.cir-18-0758.

[5] LIU Y N, ZHANG H, ZHANG L, CAI T T, HUANG D J, HE J, et al. Sphingosine 1 phosphate receptor-1 (S1P1) promotes tumor-associated regulatory T cell expansion: leading to poor survival in bladder cancer. Cell death \& disease. 2019; 10(2): 50. doi:https://doi.org/10.1038/s41419-018-1298-y.

[6] MORALES A, EIDINGER D, BRUCE A W. Intracavitary Bacillus Calmette-Guerin in the treatment of superficial bladder tumors. The Journal of urology. 1976; 116(2): 180-3. doi:https://doi.org/10.1016/j.juro.2016.10.101.

[7] MENG M V, GSCHWEND J E, SHORE N, GROSSFELD G D, MOSTAFID H, BLACK P C. Emerging Immunotherapy Options for BCG-unresponsive Non-muscle-invasive Bladder Cancer. The Journal of urology. 2019: doi:https://doi.org/10.1097/ju.0000000000000297.

[8] LIMA L, OLIVEIRA D, TAVARES A, AMARO T, CRUZ R, OLIVEIRA M J, et al. The predominance of M2polarized macrophages in the stroma of low-hypoxic bladder tumors is associated with BCG 
immunotherapy failure. Urologic oncology. 2014; 32(4): 449-57.

doi:https://doi.org/10.1016/j.urolonc.2013.10.012.

[9] SURIANO F, SANTINI D, PERRONE G, AMATO M, VINCENZI B, TONINI G, et al. Tumor associated macrophages polarization dictates the efficacy of BCG instillation in non-muscle invasive urothelial bladder cancer. Journal of experimental \& clinical cancer research : CR. 2013; $32: 87$. doi:https://doi.org/10.1186/1756-9966-32-87.

[10] MIYAKE M, TATSUMI Y, GOTOH D, OHNISHI S, OWARI T, IIDA K, et al. Regulatory T Cells and TumorAssociated Macrophages in the Tumor Microenvironment in Non-Muscle Invasive Bladder Cancer Treated with Intravesical Bacille Calmette-Guerin: A Long-Term Follow-Up Study of a Japanese Cohort. International journal of molecular sciences. 2017; 18(10): doi:https://doi.org/10.3390/ijms18102186.

[11] CHIANG C S, FU S Y, WANG S C, YU C F, CHEN F H, LIN C M, et al. Irradiation promotes an m2 macrophage phenotype in tumor hypoxia. Frontiers in oncology. 2012; 2: 89. doi:https://doi.org/10.3389/fonc.2012.00089.

[12] MUROYAMA Y, NIRSCHL T R, KOCHEL C M, LOPEZ-BUJANDA Z, THEODROS D, MAO W, et al. Stereotactic Radiotherapy Increases Functionally Suppressive Regulatory T Cells in the Tumor Microenvironment. Cancer immunology research. 2017; 5(11): 992-1004. doi:https://doi.org/10.1158/2326-6066.cir-17-0040.

[13] OZPISKIN O M, ZHANG L, LI J J. Immune targets in the tumor microenvironment treated by radiotherapy. Theranostics. 2019; 9(5): 1215-31. doi:https://doi.org/10.7150/thno.32648.

[14] CHEN B, KHODADOUST M S, LIU C L, NEWMAN A M, ALIZADEH A A. Profiling Tumor Infiltrating Immune Cells with CIBERSORT. Methods in molecular biology (Clifton, NJ). 2018; 1711: 243-59. doi:https://doi.org/10.1007/978-1-4939-7493-1_12.

[15] BRUNO A, MORTARA L, BACI D, NOONAN D M, ALBINI A. Myeloid Derived Suppressor Cells Interactions With Natural Killer Cells and Pro-angiogenic Activities: Roles in Tumor Progression. Frontiers in immunology. 2019; 10: 771. doi:https://doi.org/10.3389/fimmu.2019.00771.

[16] MOORE N, DOTY D, ZIELSTORFF M, KARIV I, MOY L Y, GIMBEL A, et al. A multiplexed microfluidic system for evaluation of dynamics of immune-tumor interactions. Lab on a chip. 2018; 18(13): 1844-58. doi:https://doi.org/10.1039/c8lc00256h.

[17] UMANSKY V, ADEMA G J, BARAN J, BRANDAU S, VAN GINDERACHTER J A, HU X, et al. Interactions among myeloid regulatory cells in cancer. Cancer immunology, immunotherapy : Cll. 2019; 68(4): 645-60. doi:https://doi.org/10.1007/s00262-018-2200-6.

[18] NIU S, WEN G, REN Y, LI Y, FENG L, WANG C, et al. Predictive Value of Primary Tumor Site for Locoregional Recurrence in Early Breast Cancer Patients with One to Three Positive Axillary Lymphadenophy. 
Journal of Cancer. 2017; 8(12): 2394-400. doi:https://doi.org/10.7150/jca.19722.

[19] BASKAR R, LEE K A, YEO R, YEOH K W. Cancer and radiation therapy: current advances and future directions. International journal of medical sciences. 2012; 9(3): 193-9.

doi:https://doi.org/10.7150/ijms.3635.

[20] GIANFALDONI S, GIANFALDONI R, WOLLINA U, LOTTI J, TCHERNEV G, LOTTI T. An Overview on Radiotherapy: From Its History to Its Current Applications in Dermatology. Open access Macedonian journal of medical sciences. 2017; 5(4): 521-5. doi:https://doi.org/10.3889/oamjms.2017.122.

[21] GUO Q, JIN Z. New Mechanisms of Tumor-Associated Macrophages on Promoting Tumor Progression: Recent Research Advances and Potential Targets for Tumor Immunotherapy. Journal of immunology research. 2016; 2016: 9720912. doi:10.1155/2016/9720912.

[22] KUNG W H, YU C F, LEE A C, YANG C D, LIU Y C, CHEN F H, et al. Gene expression profiling of tumorassociated macrophages after exposure to single-dose irradiation. Computational biology and chemistry. 2017; 69: 138-46. doi:https://doi.org/10.1016/j.compbiolchem.2017.04.010.

[23] ZHUANG X, ZHANG H, HU G. Cancer and Microenvironment Plasticity: Double-Edged Swords in Metastasis. Trends in pharmacological sciences. 2019: doi:https://doi.org/10.1016/j.tips.2019.04.005.

[24] ZHANG X, ASHCRAFT K A, BETOF WARNER A. Can Exercise-Induced Modulation of the Tumor Physiologic Microenvironment Improve Antitumor Immunity? 2019: doi:https://doi.org/10.1158/00085472.can-18-2468.

[25] ZHANG S, ZHANG E, LONG J, HU Z, PENG J, LIU L, et al. Immune Infiltration in Renal Cell Carcinoma. Cancer science. 2019: doi:https://doi.org/10.1111/cas.13996.

[26] OJALVO L S, WHITTAKER C A, CONDEELIS J S, POLLARD J W. Gene Expression Analysis of Macrophages That Facilitate Tumor Invasion Supports a Role for Wnt-Signaling in Mediating Their Activity in Primary Mammary Tumors. The Journal of Immunology. 2010; 184(2): 702-12. doi:https://doi.org/10.4049/jimmunol.0902360.

[27] TAKAYAMA H, NISHIMURA K, TSUJIMURA A, NAKAI Y, NAKAYAMA M, AOZASA K, et al. Increased infiltration of tumor associated macrophages is associated with poor prognosis of bladder carcinoma in situ after intravesical bacillus Calmette-Guerin instillation. The Journal of urology. 2009; 181(4): 1894900. doi:https://doi.org/10.1016/j.juro.2008.11.090.

[28] RUBIO C, MUNERA-MARAVILLA E, LODEWIJK I, SUAREZ-CABRERA C, KARAIVANOVA V, RUIZPALOMARES R, et al. Macrophage polarization as a novel weapon in conditioning tumor microenvironment for bladder cancer: can we turn demons into gods? 2019; 21(4): 391-403. doi:https://doi.org/10.1007/s12094-018-1952-y. 
[29] ZHANG E, DAI F, MAO Y, HE W, LIU F, MA W, et al. Differences of the immune cell landscape between normal and tumor tissue in human prostate. Clinical and Translational Oncology. 2019: doi:https://doi.org/10.1007/s12094-019-02128-5.

[30] RIGONI A, COLOMBO M P, PUCILLO C. The Role of Mast Cells in Molding the Tumor Microenvironment. Cancer microenvironment : official journal of the International Cancer Microenvironment Society. 2015; 8(3): 167-76. doi:https://doi.org/10.1007/s12307-014-0152-8.

[31] DOWELL A C. Interleukin-17-positive mast cells influence outcomes from BCG for patients with CIS: Data from a comprehensive characterisation of the immune microenvironment of urothelial bladder cancer. Oncoimmunology. 2017; 12(9): e0184841. doi:https://doi.org/10.1080/2162402x.2018.147431710.1371/journal.pone.0184841.

[32] LIU Z, ZHU Y, XU L, ZHANG J, XIE H. Tumor stroma-infiltrating mast cells predict prognosis and adjuvant chemotherapeutic benefits in patients with muscle invasive bladder cancer. 2018; 7(9): e1474317. doi:https://doi.org/10.1080/2162402x.2018.1474317.

[33] BOSTROM M M, IRJALA H, MIRTTI T, TAIMEN P, KAUKO T, ALGARS A, et al. Tumor-Associated Macrophages Provide Significant Prognostic Information in Urothelial Bladder Cancer. PloS one. 2015; 10(7): e0133552. doi:https://doi.org/10.1371/journal.pone.0133552.

[34] PICHLER R, FRITZ J, ZAVADIL C, SCH FER G, CULIG Z, BRUNNER A. Tumor-infiltrating immune cell subpopulations influence the oncologic outcome after intravesical Bacillus Calmette-Guérin therapy in bladder cancer. Oncotarget. 2016; 7(26): 39916-30. doi:https://doi.org/10.18632/oncotarget.9537.

[35] WEICHSELBAUM R R, LIANG H, DENG L, FU Y-X. Radiotherapy and immunotherapy: a beneficial liaison? Nature Reviews Clinical Oncology. 2017; 14: 365.

doi:https://doi.org/10.1038/nrclinonc.2016.211.

[36] SHABASON J E, MINN A J. Radiation and Immune Checkpoint Blockade: From Bench to Clinic. Seminars in Radiation Oncology. 2017; 27(3): 289-98. doi:https://doi.org/10.1016/j.semradonc.2017.03.002.

[37] SOLANKI A A, BOSSI A, EFSTATHIOU J A, LOCK D, MONDINI M, RAMAPRIYAN R, et al. Combining Immunotherapy with Radiotherapy for the Treatment of Genitourinary Malignancies. European urology oncology. 2019; 2(1): 79-87. doi:https://doi.org/10.1016/j.euo.2018.09.013.

[38] WEI L, JIN Z, YANG S, XU Y, ZHU Y, JI Y. TCGA-assembler 2: software pipeline for retrieval and processing of TCGA/CPTAC data. Bioinformatics (Oxford, England). 2018; 34(9): 1615-7. doi:10.1093/bioinformatics/btx812.

[39] ZHU Y, QIU P, JI Y. TCGA-assembler: open-source software for retrieving and processing TCGA data. Nat Methods. 2014; 11(6): 599-600. doi:10.1038/nmeth.2956. 


\section{Tables}

Table 1. Baseline patient and primary tumor characteristics

\begin{tabular}{|c|c|c|c|}
\hline Variable & No. of samples & $\%$ & Valid \% \\
\hline \multicolumn{4}{|l|}{ age at diagnosis, $\mathrm{y}$} \\
\hline$\geq 60$ & 324 & 78.26 & 78.64 \\
\hline$\square 60$ & 88 & 21.26 & 21.36 \\
\hline Missing & 2 & 0.48 & \\
\hline \multicolumn{4}{|l|}{ gender } \\
\hline male & 304 & 73.43 & 73.79 \\
\hline female & 108 & 26.09 & 26.21 \\
\hline Missing & 2 & 0.48 & \\
\hline \multicolumn{4}{|l|}{ tumor grade } \\
\hline low grade & 21 & 5.07 & 5.13 \\
\hline high grade & 388 & 93.72 & 94.87 \\
\hline Missing & 5 & 1.21 & \\
\hline \multicolumn{4}{|l|}{ tumor status } \\
\hline with tumor & 137 & 33.09 & 36.83 \\
\hline tumor free & 235 & 56.76 & 63.17 \\
\hline Missing & 42 & 10.14 & \\
\hline \multicolumn{4}{|c|}{ metastasis pathologic } \\
\hline M0 & 196 & 47.34 & 94.69 \\
\hline M1 & 11 & 2.66 & 5.31 \\
\hline Missing & 207 & 50 & \\
\hline
\end{tabular}

Table2. 22 TIICs proportion in normal tissue and in BLCAs tissue. 
Normal

B cells naive

B cells memory

Plasma cells

T cells CD8

T cells CD4 memory resting

T cells CD4 memory activated $0.020 \pm 0.006$

$\mathrm{T}$ cells follicular helper

$0.026 \pm 0.006$

$0.029 \pm 0.009$

$0.015 \pm 0.009$

$0.004 \pm 0.003$

$0.039 \pm 0.007$

$0.021 \pm 0.005$

$0.010 \pm 0.004$

$0.027 \pm 0.009$

$0.139 \pm 0.019$

$0.037 \pm 0.010$

$0.021 \pm 0.006$

$0.119 \pm 0.026$

$0.040 \pm 0.021$

$0.006 \pm 0.002$

$0.009 \pm 0.004$

Dendritic cells resting

Dendritic cells activated

Mast cells resting

Mast cells activated

Eosinophils

Neutrophils
BLCA

$0.035 \pm 0.003$

$0.007 \pm 0.002$

$0.056 \pm 0.003$

$0.107 \pm 0.004$

$0.125 \pm 0.004$

$0.030 \pm 0.002$

$0.044 \pm 0.002$

$0.046 \pm 0.002$

$0.003 \pm 0.001$

$0.017 \pm 0.001$

$0.0030 \pm 0.002$

$0.015 \pm 0.001$

0.364

$0.126 \pm 0.006$

0.000
0.002

0.693

$0.063 \pm 0.003$

$0.130 \pm 0.004$

$0.042 \pm 0.003$

0.708

0.063

$0.048 \pm 0.003$

$0.043 \pm 0.002$

0.010

$0.015 \pm 0.002$

0.259

0.329

0.775

\section{Figures}




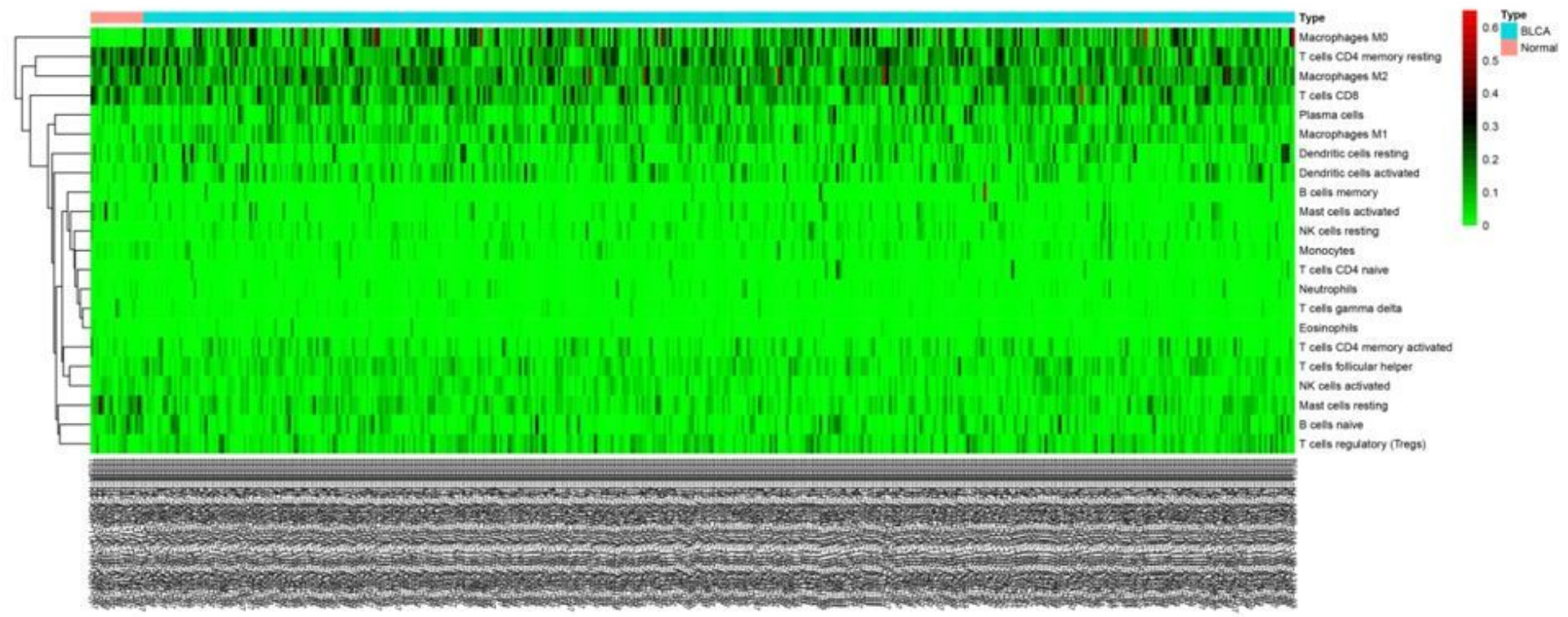

Figure 1

TIICs proportions in normal bladder tissues and BLCA tissues. CIBERSORT immune cell fractions were determined for each patient. TIICs proportion were estimated and showed in the heatmap. 


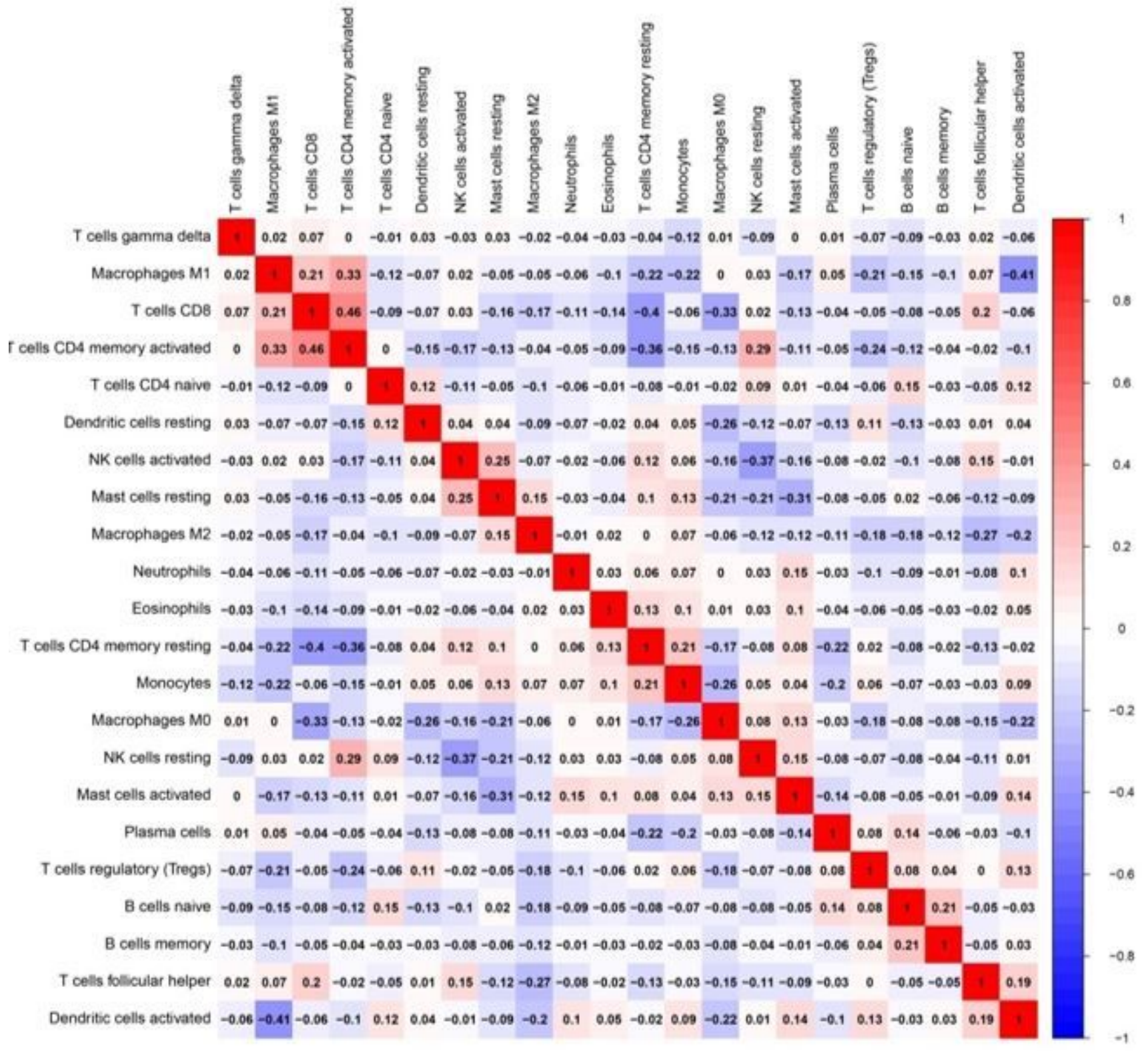

Figure 2

Correlation matrix of 22 immune cell types in bladder cancer tissues and the correlation index was calculated with corrplot Package. 
a

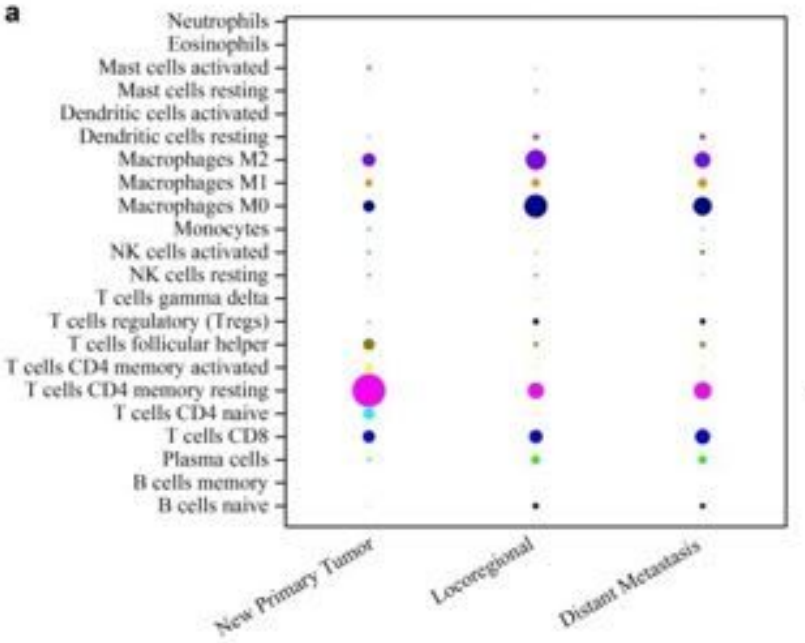

b

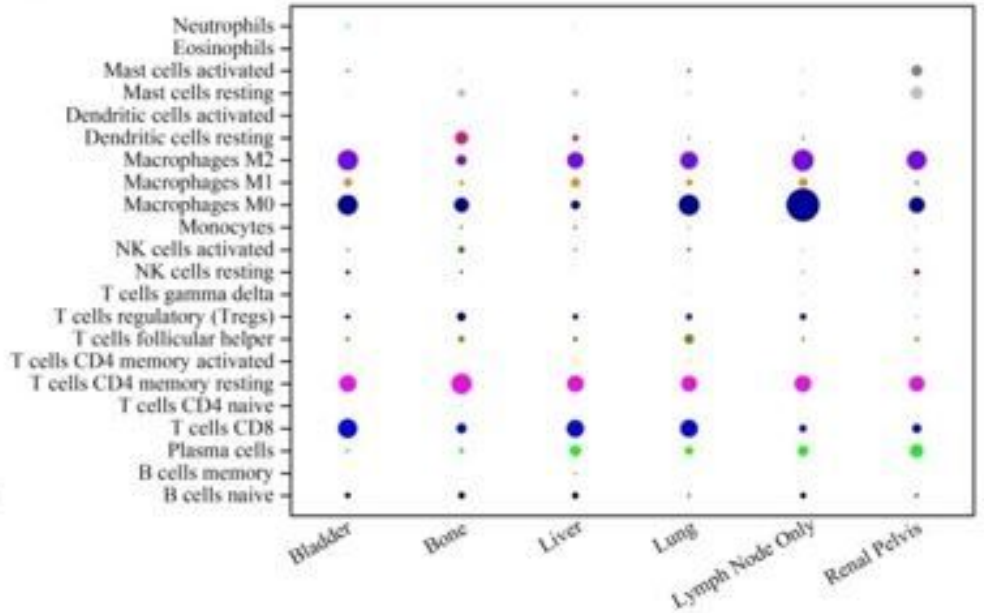

Figure 3

TIICs fraction proportions in BLCAs patients with different event types (a) and different sites (b) new tumor.
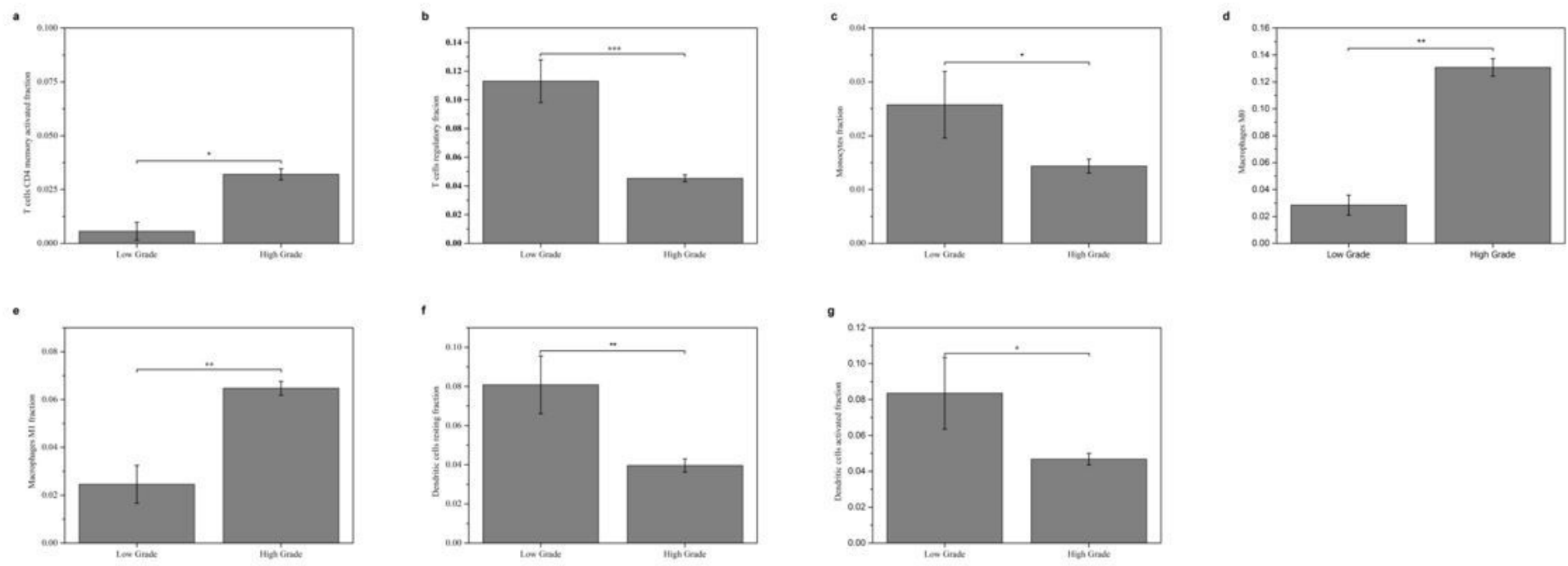

Figure 4

TIICs fraction proportions in low grade or high grade BLCAs patients. T cells CD4 memory activated e(a), T cells regulatory, (b), Monocytes (c), Macrophages M0 (d), Macrophages M1 (e), Dendritic cells resting (f) and Dendritic cells activated (g) were calculated in low grade BLCAs or high grade BLCAs. 
a

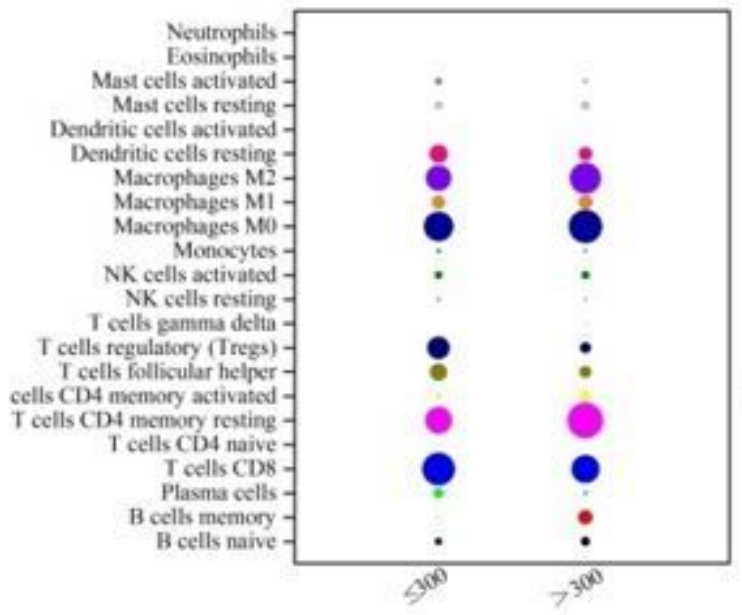

b

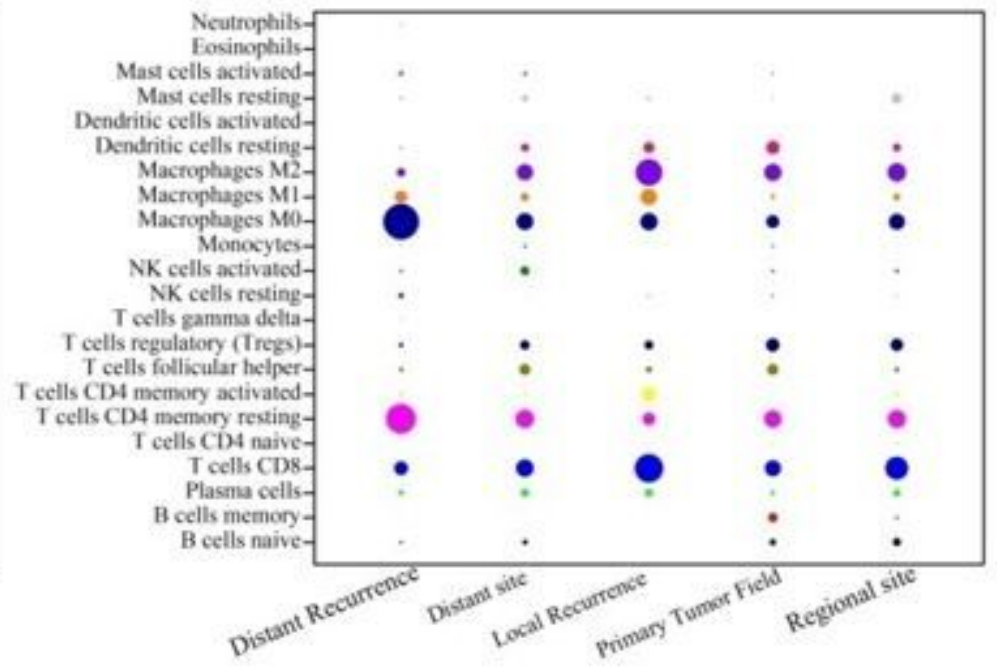

\section{Figure 5}

TIICs fraction proportions in BLCAs patients with radiotherapy. The 22 immune cells proportion in BLCAs patients accepted with different radiation dose (a) and in BLCAs patients with different radiotherapy sites 